\title{
Effect of Modification with Various Epoxide Compounds on Mechanical, Thermal, and Coating Properties of Epoxy Resin
}

\author{
Alaaddin Cerit, ${ }^{1}$ Mustafa Esen Marti, ${ }^{2}$ Ulku Soydal, ${ }^{2}$ Suheyla Kocaman, ${ }^{2}$ \\ and Gulnare Ahmetli ${ }^{2}$ \\ ${ }^{1}$ Eregli Kemal Akman Vocational School, N. Erbakan University, Konya, Turkey \\ ${ }^{2}$ Faculty of Engineering, Department of Chemical Engineering, Selcuk University, 42075 Konya, Turkey
}

Correspondence should be addressed to Gulnare Ahmetli; gahmetli@gmail.com

Received 20 April 2016; Revised 15 July 2016; Accepted 20 July 2016

Academic Editor: Hossein Roghani-Mamaqani

Copyright (C) 2016 Alaaddin Cerit et al. This is an open access article distributed under the Creative Commons Attribution License, which permits unrestricted use, distribution, and reproduction in any medium, provided the original work is properly cited.

\begin{abstract}
Epoxy resin (ER) was modified with four different epoxide compounds, 4,5-epoxy-4-methyl-pentane-2-on (EMP), 3-phenyl-1,2epoxypropane (PhEP), 1-chloro-2,3-epoxy-5-(chloromethyl)-5-hexene (CEH), and a fatty acid glycidyl ester (FAGE), to improve its chemical and physical properties. The effects of the addition and amount of these modifiers on mechanical, thermal, and coating properties were investigated. Atomic force microscopy was used to observe the changes obtained with the modification. The influence of the modifying agents on the curing process was monitored through FTIR spectroscopy. The curing degrees of ER and modified ERs (M-ERs) were found to be over 91\%. The results showed that tensile strength of ER improved till 30\% (wt.) with addition of the modifier content. Modification with EMP and PhEP remarkably enhanced the thermal stability of ER to be highly resistant to the corrosive media.
\end{abstract}

\section{Introduction}

Thermosets, such as epoxy resins (ERs), are important polymeric materials since they have been widely used as high performance materials such as adhesives, composite matrices, and anticorrosion coatings [1]. However, these thermosets have inherently low impact resistances due to their high cross-linking density, which restricts some of their applications.

In the literature, a large number of studies have been conducted on the modification of highly cross-linked ERs to improve their impact resistance $[2,3]$. For example, bisphenol-A type epoxy was modified with 4 - $(\mathrm{N}$-phthalimidophenyl) glycidyl ether (PPGE) in 5-20 wt.\% and epoxy coating with 15 wt. $\%$ of PPGE showed improved mechanical, thermal, and flame retardant properties [4]. Jin and Park studied the effects of the addition of biobased epoxy materials on the impact strengths of DGEBA epoxy system. The authors observed that the impact strength increased from 13.9 to $21.9 \mathrm{~J} / \mathrm{m}^{2}$ with the addition of $60 \mathrm{wt} . \%$ epoxidized soybean oil
(ESO) [5]. A similar trend was also reported by Miyagawa et al. using biobased neat epoxy materials containing epoxidized linseed oil [6]. In another study, Chen et al. have used n-butyl glycidyl ether (BGE) to modify diglycidyl ether of bisphenol-F (DGEBF) epoxy system and obtained enhanced impact strength with the modification. The impact strength increased by $77.6 \%$ with the addition of $40 \mathrm{phr}$ BGE compared to that of the unmodified epoxy material [7]. Yang et al. have selected two flexible polyoxypropylene diamines (D-230 and D-400) to modify ERs and reported that the impact strength increased from $19.2 \mathrm{~kJ} / \mathrm{m}^{2}$ to $53.56 \mathrm{~kJ} / \mathrm{m}^{2}$ with the addition of the diamine modifiers [8]. The polybutadiene particles have been used to enhance the properties of epoxy matrix and all modified epoxy networks exhibited higher impact resistances with respect to the neat ER [9].

In our previous study, ER has been modified with biobased and styrene-based polymers. The results indicated that the modification process enhanced several properties of ER such as surface hardness, tensile strength, percentage elongation, and stress at maximum load of the blends [10]. 
In addition to that, our recent studies have shown that the addition of some modifying agents and additives to polymer matrices significantly influenced their mechanical properties [11-13]. In the present study, ER was modified with epoxide compounds (modifiers) having ketone, ester, alkene, chloride, and phenyl groups and effects of the modifiers on the mechanical, thermal, and coating properties of ER were investigated. To the best of our knowledge, this is the first study in which ER was modified with epoxide compounds having varying functional groups.

\section{Experimental}

2.1. Materials. The modifiers, 4,5-epoxy-4-methyl-pentane-2-on, 3-phenyl-1,2-epoxypropane, 1-chloro-2,3-epoxy5-(chloromethyl)-5-hexene, and fatty acid glycidyl ester, were synthesized with the use of precursors mentioned in the following subsections. The details of the procedures were explained in these parts, too. A commercially available bisphenol-A type epoxy resin (NPEK 114, Konuray Chemical Co.) diluted with aliphatic $\mathrm{C}_{12}-\mathrm{C}_{14}$ glycidyl ether (ER) was used as the thermosetting matrix and it was cured with 30 wt.\% Epamine PC17 (a cycloaliphatic polyamine, Konuray Chemical Co.). 2,4,6-Tris(dimethylaminomethyl)phenol (Sigma-Aldrich) was utilized as the epoxy embedding medium accelerator.

\subsection{Synthesis}

2.2.1. Synthesis of 4,5-Epoxy-4-methyl-pentane-2-on (EMP). The EMP was synthesized through the oxidation of 4-methyl3 -pentene-2-on with hydrogen peroxide in basic medium. A solution of $\mathrm{NaOH}(2.0 \mathrm{~mL}, 20 \%)$ was added to the solution of 4-methyl-3-pentene-2-on (10.0 g) dissolved in diethyl ether $(10.0 \mathrm{~mL})$. Then, hydrogen peroxide $(5.0 \mathrm{~mL}, 20 \%)$ was added dropwise to the mixture at room temperature. The mixture was stirred for $2 \mathrm{~h}$ and neutralized with a diluted $\mathrm{HCl}$ solution. Diethyl ether was removed using a rotary evaporator and EMP was obtained in $70 \%$ yield after vacuum distillation at $61-62^{\circ} \mathrm{C} / 2 \mathrm{mmHg}$.

2.2.2. Synthesis of 3-Phenyl-1,2-epoxypropane (PhEP). The PhEP was synthesized from the dehydrochlorination of 1chloro-3-phenyl-2-propanol obtained through the alkylation of benzene with epichlorohydrin in the presence of $\mathrm{AlCl}_{3}$. Benzene $(78.0 \mathrm{~g})$ and $\mathrm{AlCl}_{3}(16.6 \mathrm{~g})$ were placed into a three-necked flask equipped with a mechanical stirrer, thermometer, and dropping funnel. The mixture was cooled to $0^{\circ} \mathrm{C}$ and epichlorohydrin (11.6 g) was added dropwise to the mixture. After the mixture was stirred at $10-15^{\circ} \mathrm{C}$ for $10 \mathrm{~min}, 10 \% \mathrm{HCl}$ solution was added to the mixture. Organic layer was separated, washed with water, and dried on $\mathrm{Na}_{2} \mathrm{SO}_{4}$. Most of the benzene was removed by a rotary evaporator, and then alkylation product, 1-chloro-3-phenyl2 -propanol, was obtained in $50 \%$ yield by vacuum distillation at $91^{\circ} \mathrm{C} / 2 \mathrm{mmHg}$.

At the second stage, diethyl ether $(150 \mathrm{~mL})$ and $\mathrm{KOH}$ $(56.1 \mathrm{~g}$ or $40.0 \mathrm{~g}$ of $\mathrm{NaOH})$ were added in a three-necked flask equipped with a mechanical stirrer, thermometer, and dropping funnel. 1-Chloro-3-phenyl-2-propanol (34.0 g) was added dropwise to the mixture at $15^{\circ} \mathrm{C}$. After the mixture was stirred for $2 \mathrm{~h}$, it was dried on $\mathrm{Na}_{2} \mathrm{SO}_{4}$. Diethyl ether was removed with the use of a rotary evaporator, and then the $\mathrm{PhEP}$ was obtained in $80 \%$ yield after the vacuum distillation carried out at $59-60^{\circ} \mathrm{C} / 2 \mathrm{mmHg}$.

2.2.3. Synthesis of 1-Chloro-2,3-epoxy-5-(chloromethyl)-5hexene $(\mathrm{CEH})$. The $\mathrm{CEH}$ was prepared by the dehydrochlorination reaction, which was a condensation product from 3-chloro-2-methylpropene and 2,3-dichloropropanal catalysed by $\mathrm{AlCl}_{3}$. 3-Chloro-2-methylpropene (18.0 g), $\mathrm{AlCl}_{3}$ $(3.0 \mathrm{~g})$, and benzene $(40 \mathrm{~mL})$ were placed into a three-necked flask equipped with a mechanical stirrer, thermometer, and dropping funnel. After 2,3-dichloropropanal (2.6 g) was added dropwise to the mixture, it was stirred for $2 \mathrm{~h}$ at room temperature. The mixture was neutralized by washing with water. Organic layer was treated with a solution of $\mathrm{NaOH}$ (40\%, wt.) in diethyl ether $(20 \mathrm{~mL})$. Dehydrochlorination step was completed after stirring the mixture for $3 \mathrm{~h}$. Then, the mixture was reneutralized by washing with water and dried on $\mathrm{Na}_{2} \mathrm{SO}_{4}$. Vacuum distillation of crude product at $64-66^{\circ} \mathrm{C} / 4 \mathrm{mmHg}$ gave the $\mathrm{CEH}$ in $70 \%$ yield.

2.2.4. Synthesis of Fatty Acid Glycidyl Ester (FAGE). The waste of sunflower oil as fatty acid (FA) potassium salt was supplied from Zade Chemical Industry, Konya, Turkey. The FAGE was obtained by esterification of a fatty acid (FA) potassium salt with epichlorohydrin in alkaline medium. The FA waste $(10.0 \mathrm{~g})$ and benzene $(10 \mathrm{~mL})$ were placed into a flask $(50 \mathrm{~mL})$. A solution of $\mathrm{KOH}(4 \mathrm{~mL}, 40 \%)$ was added to the mixture followed by dropwise addition of epichlorohydrin (3.0 g) within $20-30 \mathrm{~min}$ at $40^{\circ} \mathrm{C}$. After the completion of the addition, temperature was increased to $70-80^{\circ} \mathrm{C}$ and the mixture was refluxed for $5 \mathrm{~h}$. The FAGE was obtained by distillation under reduced pressure.

2.3. Modifying ER with the Synthesized Epoxide Compounds. The synthesized epoxide compounds were mixed with epoxy matrix in weight percentages of $10,20,30,40$, and $50 \%$. The mixtures were stirred at $1200 \mathrm{rpm}$ for an hour using a Heidolph RZR1 stirrer. Afterwards, Epamine PC17 hardener (30 wt.\%) and epoxy accelerator (1 wt.\%) were added and the final mixture was transferred into the mould. Samples were prepared in stainless steel moulds according to ASTM D638 standard. The samples were cured for $24 \mathrm{~h}$ at $40^{\circ} \mathrm{C}$ followed by a postcuring process for $48 \mathrm{~h}$ at $120^{\circ} \mathrm{C}$.

\subsection{Analysis and Testing}

2.4.1. Determination of Epoxy Group ( $\mathrm{O}$ ). In order to determine the percentage of epoxy group, $0.5 \mathrm{~g}$ of sample and $25 \mathrm{~mL}$ of a solvent mixture $(60 \mathrm{~mL}$ of acetone $+1.5 \mathrm{~mL}$ of concentrated $\mathrm{HCl}$ ) were placed into a $250 \mathrm{~mL}$ flask. The mixture was stirred for $2 \mathrm{~h}$ at room temperature. The epoxy groups were cleaved by the addition of excess HCI. The 
remaining $\mathrm{HCI}$ was titrated with $0.1 \mathrm{~N} \mathrm{KOH}$ and its amount was calculated. The percentage of epoxy group was calculated using

$$
\text { Epoxy groups, } \%=\frac{\left(V_{1}-V_{2}\right) \times 0.0043 \times F \times 100}{m},
$$

where $V_{1}$ is the volume $(\mathrm{mL})$ of $0.1 \mathrm{~N} \mathrm{KOH}$ used for the titration of control, $V_{2}$ is the volume $(\mathrm{mL})$ of $0.1 \mathrm{~N} \mathrm{KOH}$ used for the titration of sample, $F$ is the titration factor for $0.1 \mathrm{~N}$ $\mathrm{KOH}$ solution, $m$ is the amount ( $\mathrm{g}$ ) of the sample analysed, and 0.0043 is the number of epoxy groups corresponding to $1 \mathrm{~mL}$ of $0.1 \mathrm{~N} \mathrm{KOH} \mathrm{[14].}$

2.4.2. FTIR Analysis. The FTIR spectra of the synthesized epoxide compounds and M-ERs were taken with the use of Bruker-Platinum ATR-vertex 70.

2.4.3. AFM Analysis. The morphology of M-ERs was examined with a Solver $\mathrm{P} 47 \mathrm{H}$ atomic force microscope (AFM, NT-MTD, Moscow, Russia) operating in tapping mode in air at room temperature. Diamond-like carbon (DLC) coated NSG01 DLC silicon cantilevers (from NT-MTD) with a $2 \mathrm{~nm}$ tip apex curvature were used at the resonance frequency of $150 \mathrm{kHz}$. The Nova 914 software package was used to control the system and for the analysis of the AFM images.

2.4.4. Mechanical Testing. A Shore Durometer TH 210 tester was used for measuring the hardness of the samples. The resistances to stretch properties were determined by Stretch and Pressing Equipment TST-Mares/TS-mxe.

2.4.5. Thermal Analysis. Thermal analysis experiment was carried out using a NETZCH-Geratebau $\mathrm{GmbH}$ model thermogravimetric analyser. The samples were heated under nitrogen atmosphere from $50^{\circ} \mathrm{C}$ to $800^{\circ} \mathrm{C}$ at a heating rate of $10^{\circ} \mathrm{C} \cdot \mathrm{min}^{-1}$. The CEAST HDT-VICAT test equipment was used for measuring the softening point.

2.4.6. Water Sorption Testing. The percentage of water sorption was determined by a gravimetric method. The M-ERs were stored in deionized water at room temperature for 30 days. To explore the temperature effect on water sorption, the same procedure was carried out at $45^{\circ} \mathrm{C}$. The samples were daily taken and weighed after drying the surface. Water sorption of the coatings was calculated using

$$
\text { Sorption } \%=\frac{\left(W_{t}-W_{0}\right)}{W_{0}} \times 100,
$$

where $W_{0}$ and $W_{t}$ are the mass of the dry sample and that of the sample at a corresponding time, respectively.

2.4.7. Adhesion and Corrosion Testing. The adhesion property of M-ER coatings was determined by the "lattice notch method." The adhesion capability of the M-ERs was determined using a metal (cold rolled carbon steel) that contains C (0.2\%), Mn (1.5\%), Si (0.1\%), P (0.01\%), and S (0.008\%) with<smiles>CC(=O)C1OC1(C)C</smiles>

EMP<smiles>C=C(CCl)CC1OC1CCl</smiles>

$\mathrm{CEH}$<smiles>c1ccc(CC2CO2)cc1</smiles>

PhEP

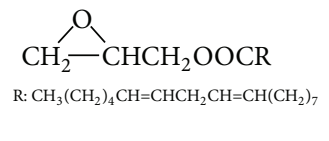

FAGE
FIgURE 1: Chemical formula of synthesized compounds.

the dimensions of $50 \mathrm{~mm} \times 100 \mathrm{~mm} \times 1 \mathrm{~mm}$. The tested side of the rod was blasted and cleaned. M-ER coating was deposited as a layer $(100-120 \mu \mathrm{m})$ over the metal and the material was dried for $72 \mathrm{~h}$ at $120^{\circ} \mathrm{C}$.

According to the "lattice notch method," a thin epoxy layer was divided into small squares $(1 \mathrm{~mm} \times 1 \mathrm{~mm})$ by a razor blade. Insulating tape $(10-100 \mathrm{~mm})$ was placed over these squares and the tape was suddenly pulled. In this process, a portion of small squares was separated from the surface of the metal and another portion remains on the surface. Therefore, adhesion percent was calculated from the number of small squares still remaining on the metal surface using

$$
\text { Adhesion } \%=\left[\frac{(a-b)}{a}\right] \times 100,
$$

where $a$ is the total number of squares and $b$ is the number of squares removed from the substrate [15].

The metal surfaces coated with M-ER films $(100-120 \mu \mathrm{m}$ thick) were immersed in $3 \% \mathrm{NaCl}, 10 \% \mathrm{NaOH}$, and $10 \% \mathrm{HCl}$ solutions for 15 days. After the removal of the coated metals from these solutions, amount of defects (swelling, colour changes, blurring, etc.) observed by naked eye was taken as a measure of the corrosion resistance [16].

\section{Results and Discussion}

3.1. Characterization of Epoxide Compounds. Figure 1 shows the structures of the synthesized epoxide compounds EMP, $\mathrm{PhEP}, \mathrm{CEH}$, and FAGE. Their chemical structures were confirmed by infrared spectra (Figure 2) and the related data are given in Table 1 . Characteristic bands belonging to $\mathrm{C}-\mathrm{H}$ vibrations were observed in the regions of 2830 $3000,1600,1400-1450$, and $1375 \mathrm{~cm}^{-1}$ for aliphatic C-H stretching, aromatic $\mathrm{C}=\mathrm{C}$ stretching, aliphatic $\mathrm{C}-\mathrm{H}$ bending, and $\mathrm{C}-\mathrm{H}$ rock, respectively. The sharp bands observed at 745 and $1166 \mathrm{~cm}^{-1}$ can be assigned to $\mathrm{C}-\mathrm{Cl}$ and $\mathrm{C}-\mathrm{O}-\mathrm{C}$ groups. Also, the presence of epoxide group was characterized by the appearance of typical bands at 1250,913 , and $830 \mathrm{~cm}^{-1}$ corresponding to $\mathrm{C}-\mathrm{O}-\mathrm{C}$ stretching of ethers and $\mathrm{C}-\mathrm{O}$ and $\mathrm{C}-\mathrm{O}-\mathrm{C}$ stretching of oxirane group, respectively. These results showed that epoxy compounds were successfully synthesized.

The end groups (epoxy, hydroxide, glycol, chlorine, and bisphenol-A) were determined by classical chemical methods [17]. The presence of epoxide groups was also proved by acid 
TABLE 1: FTIR bands appear in the spectra of EMP, PhEP, CEH, and FAGE.

\begin{tabular}{|c|c|c|c|c|}
\hline \multirow{2}{*}{ Functional group } & \multicolumn{4}{|c|}{ Bands, $\mathrm{cm}^{-1}$} \\
\hline & For EMP & For PhEP & For CEH & For FAGE \\
\hline Epoxide & $1250 ; 915 ; 828$ & $1250 ; 913 ; 830$ & $1250 ; 913 ; 875 ; 830$ & $913 ; 830$ \\
\hline Fatty acid $-\left(\mathrm{CH}_{2}\right)_{n}$ - unit & - & - & - & 720 \\
\hline Ester C-O-C & - & - & - & 1166 \\
\hline $\mathrm{C}=\mathrm{O}$ ester & - & - & - & 1750 \\
\hline $\mathrm{R}_{2} \mathrm{C}=\mathrm{CH}_{2}$ & - & - & 1655 & - \\
\hline $\begin{array}{l}\text { Aliphatic C-H plane in bending (for } \\
\mathrm{CH}_{2} \text { ) }\end{array}$ & - & 1400 & 1450 & 1450 \\
\hline Aliphatic - $\mathrm{CH}$ grubu & - & 1375 & 1375 & 1375 \\
\hline Alkane C-H stretching & 2975 & 3000 & 3000 & $2833 ; 2950$ \\
\hline $\begin{array}{l}\text { Aliphatic C-H plane off bending } \\
\left(\text { for } \mathrm{CH}_{2}\right)\end{array}$ & 1100 & 1100 & 1056 & 1100 \\
\hline Adjacent to the carbonyl $\mathrm{CH}_{2}$ & 1410 & - & - & - \\
\hline Aromatic $\mathrm{C}=\mathrm{C}$ & - & 1600 & - & - \\
\hline Aromatic C-C stretching & - & 1500 & - & - \\
\hline Monosubstituted benzene & - & 770 & - & - \\
\hline $\begin{array}{l}\text { Aromatic C-H plane in bending (for } \\
\text { monosubstituted benzene) }\end{array}$ & - & 1030 & - & - \\
\hline Ketone $\mathrm{C}=\mathrm{O}$ stretching & 1722 & - & - & - \\
\hline $\mathrm{C}-\mathrm{Cl}$ & - & - & 745 & - \\
\hline
\end{tabular}

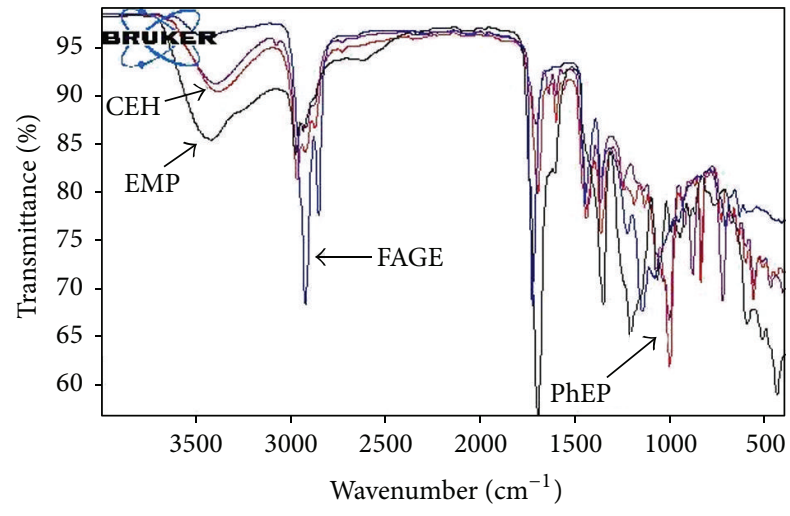

FIGURE 2: FTIR spectra of synthesized epoxide compounds.

TABLE 2: Epoxide numbers.

\begin{tabular}{lc}
\hline Modifier & Epoxide number (\%) \\
\hline EMP & 13.48 \\
PhEP & 8.43 \\
CEH & 7.30 \\
FAGE & 10.50 \\
\hline
\end{tabular}

titration. The results are given in Table 2. The epoxy content of the synthesized compounds varied in the range of 7.30$13.48 \%$.

3.2. The Explanation for Substances Used in M-ER Preparation. Most of the mechanical properties of the ERs are closely related to the chemical composition of the material. The liquid aliphatic polyamines such as polyethylene polyamines (PEPAs) are among the first curing agents used with epoxies. Curing of epoxy matrices with these agents can be successfully carried out even at room temperature. Compared to aliphatic amines, cycloaliphatic amines produce cured resins having improved thermal resistance and toughness. They can provide an excellent balance of the properties such as fast curing, low viscosity, low toxicity, good adhesion to damp concrete, and excellent colour stability. However, they are more expensive than other types of curing agents [18]. In the present study, a cycloaliphatic polyamine was selected as the curing agent.

\subsection{Characterization of $M-E R s$}

3.3.1. Curing Degrees of ER and M-ERs. Almost all ERs were converted into solid, infusible, and insoluble threedimensional thermoset networks by the curing process with the use of appropriate cross-linkers. Optimum performance properties can be obtained by cross-linking using the appropriate ERs and cross-linkers, often called hardeners or curing agents. Besides influencing the viscosity and reactivity of the formulation, curing agents also determine the types of chemical bonds formed and the degree of cross-linking that will occur. These affect the chemical resistance, electrical properties, mechanical properties, and heat resistance of the cured thermosets [19].

Curing degrees of ER and M-ERs were determined by FTIR spectra. Epoxy group showed typical bands at the regions of 830,913 , and $1250 \mathrm{~cm}^{-1}$ [20]. The absorption band 


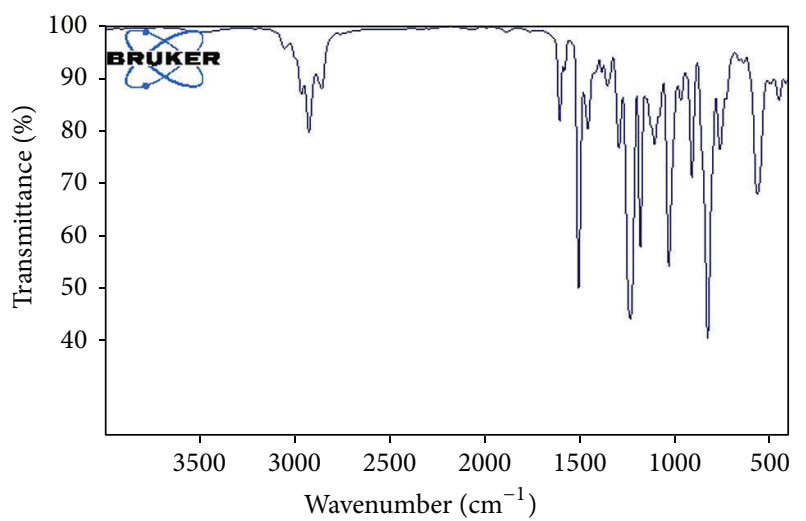

(a)

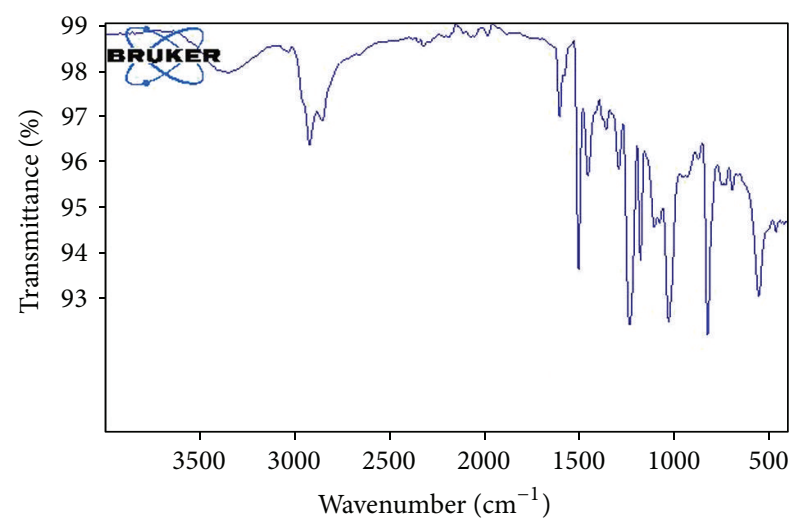

(b)

FIGURE 3: FTIR spectra of uncured (a) and cured (b) ER.

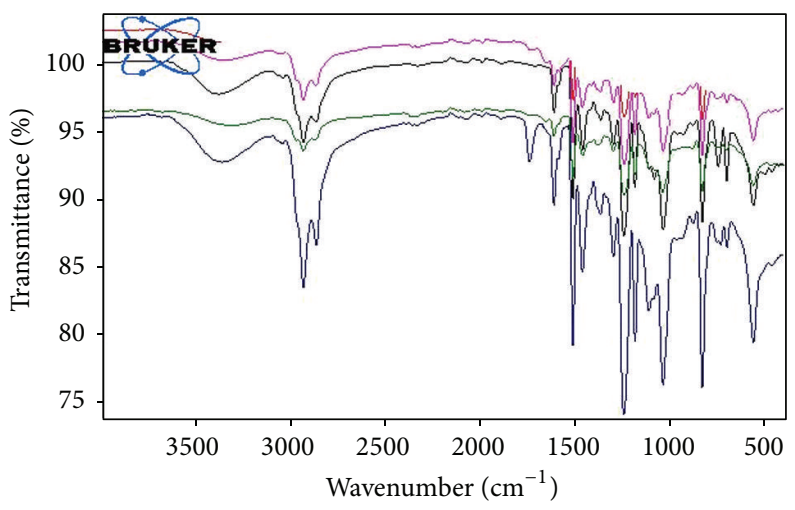

FIgURE 4: FTIR spectra of cured M-ERs.

at $913 \mathrm{~cm}^{-1}$ was used for the determination of curing degree because a band at $830 \mathrm{~cm}^{-1}$ possibly overlapped with a C$\mathrm{H}$ vibration band of aromatic ring [21,22]. As intensity of the absorption band at $913 \mathrm{~cm}^{-1}$ decreased, curing degree increased. Thus, the results showed that the absorption band at $913 \mathrm{~cm}^{-1}$ was sensitive to the change of epoxy group and in accordance with Beer-Lambert law [23, 24].

As seen from Figures 3 and 4, the absorption band at $913 \mathrm{~cm}^{-1}$ observed in FTIR spectra of ER completely disappeared upon modifying with EMP, PhEP, CEH, and FAGE. This indicated that all modification processes were successful. According to the Beer-Lambert law, the absorption peak at $1600-1616 \mathrm{~cm}^{-1}$ belongs to the benzene ring and can be considered as the internal standard. Thus, the degree of curing can be determined from FTIR spectra of ER and MERs [25] using

$$
\alpha=\frac{A_{\text {cured }}^{1600} A_{\text {uncured }}^{913}-A_{\text {cured }}^{913} A_{\text {uncured }}^{1600}}{A_{\text {cured }}^{1600} A_{\text {uncured }}^{913}},
$$

where $A_{\text {uncured }}$ is the original absorbance of epoxy without curing while $A_{\text {cured }}$ is the absorbance of the cured M-ERs.
TABLE 3: Curing degrees of the neat ER and M-ERs with $30 \mathrm{wt} . \%$ of modifiers.

\begin{tabular}{lc}
\hline Sample & Curing degree (\%) \\
\hline Neat ER & 91.70 \\
Modified ER with EMP & 99.20 \\
Modified ER with PhEP & 92.89 \\
Modified ER with CEH & 92.85 \\
Modified ER with FAGE & 93.11
\end{tabular}

Table 3 shows the curing degrees of ER and the M-ERs with $30 \mathrm{wt} . \%$ modifier content. The curing degrees of $\mathrm{M}$ ERs were found to be similar or higher than those of ER. This result was attributed to the presence of epoxy group in the structure of modifiers. As it is known, epoxy ring is abnormally reactive compared to noncyclic and other cyclic ethers. It has been postulated that the highly strained bond angles, along with the polarization of $\mathrm{C}-\mathrm{C}$ and $\mathrm{C}-\mathrm{O}$ bonds, account for the high reactivity of epoxide. Since ERs contain two chemically reactive functional groups, epoxy and hydroxyl, they are mostly cured via epoxy group. Reaction of epoxy groups involves opening of oxirane ring and formation of longer, linear C-O bonds. This feature accounts for the low shrinkage and good dimensional stability of cured epoxides [18].

3.3.2. AFM Analysis. Atomic force microscopy is one of the most important microscopic techniques and used in the analyses of the surfaces of polymers at nanometer scale. The additional advantage of using AFM is that it can give distinguished surface topography and surface heterogeneity. The representative 3D surface morphologies of ER and MERs are given in Figures 5 and 6, respectively. As expected, their surface morphologies were quite different because the modifying agents have different chemical structures. As can be easily seen in AFM images, the heights on the surface of ER (Figure 5) were not intense. In addition, modification process increased the surface porosity of ER. Increased roughness was observed at ER-PhEP (Figure 6(b)) compared to the other 


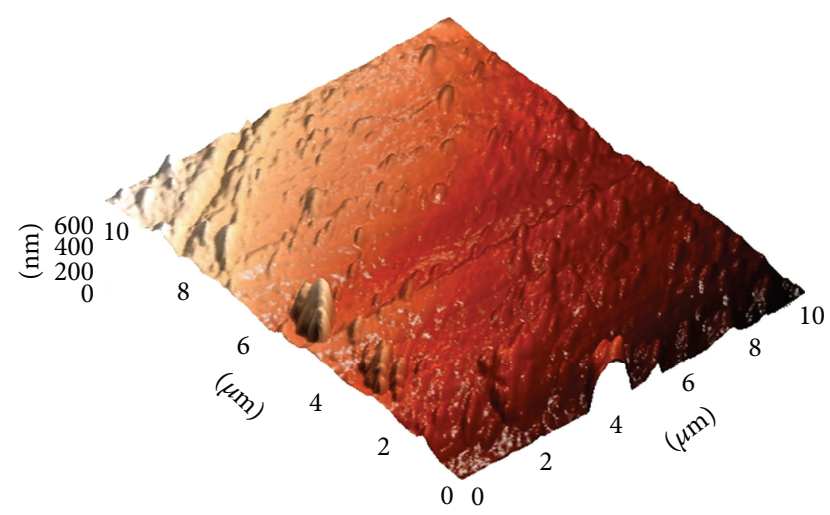

FIgURE 5: AFM image of neat ER.

blends, ER-EMP, ER-CEH, and ER-FAGE, whose surfaces were relatively bumpy (Figures 6(a), 6(c), and 6(d), resp.). This is most probably due to the bigger phenyl groups in ERPhEP with respect to ketone or other aliphatic groups. As known, the ability of additives to migrate to the surface can be defined by several factors such as size, mobility, end-group functionality, relative composition, and molecular architecture. Generally, the existence of the modifiers having various chemical structures makes the polymer surface rougher.

3.3.3. Mechanical Properties. The strength and toughness of ERs below the glass transition temperature $\left(T_{g}\right)$ depend on the mechanism of the movement of short segments in the solid state. Above $T_{g}$, mechanical properties are influenced by cross-linking density and molecular weight [17]. The structure of the side-chain substituents on the polymer backbone is the major compositional factor impacting the polymer functionality. Important aspects of substitutions are chemical structure of the substituents, extent of backbone substitution, and uniformity of the substitution. The nature of the side-chain substituent type also significantly impacts the mechanical properties. Increasing the amount of highly polar, ionic side chains tends to result in an increase in tensile strength. Polarity order of the functional groups is given as follows: amide $>$ carboxylic acid $>$ hydroxyl $>$ ketone $\sim$ aldehyde $>$ amine $>$ ester $>$ ether $>$ alkene $>$ alkane. Besides, polarity of aromatic compounds and conjugated polyenes are higher than those of alkanes and alkenes [26]. Sethuraman et al. investigated the effect of side group structure on the compressive strength of novel biodegradable polyphosphazene based polymers [27]. The results of mechanical tests demonstrated that the nature and the ratio of the pendant groups attached to the polymer backbone played a significant role in determining the mechanical properties of the resulting polymer. The compressive strength of polymer with aliphatic alanine side group was significantly higher than polymers with aromatic alanine groups [27]. Cerit et al. [28] reported that the highest elongation at break was obtained as $2.91 \%$ with a condensation product of modified polystyrene- (MPS) crotonaldehyde among the aliphatic aldehydes and as $1.86 \%$ with a condensation product of MPS-cinnamaldehyde among the aromatic aldehydes. Additionally, condensation reaction
TABLE 4: Effect of modifier type and amount on mechanical properties.

\begin{tabular}{|c|c|c|c|c|}
\hline $\begin{array}{l}\text { Modifier } \\
\text { (wt.\%) }\end{array}$ & $\begin{array}{c}\text { Elongation } \\
\text { at break (\%) }\end{array}$ & $\begin{array}{c}\text { Tensile } \\
\text { strength } \\
(\mathrm{MPa})\end{array}$ & $\underset{(\mathrm{GPa})}{e \text {-modulus }}$ & $\begin{array}{l}\text { Hardness } \\
\text { (Shore D) }\end{array}$ \\
\hline \multicolumn{5}{|c|}{ For neat ER } \\
\hline- & 0.487 & 41.75 & 5.59 & 75.5 \\
\hline \multicolumn{5}{|c|}{ For M-ER with EMP } \\
\hline 10 & 0.542 & 59 & 6.50 & 83.9 \\
\hline 20 & 0.545 & 58 & 5.53 & 81.0 \\
\hline 30 & 0.556 & 56 & 4.97 & 81.5 \\
\hline 40 & 0.559 & 56 & 4.80 & 73.0 \\
\hline \multicolumn{5}{|c|}{ For M-ER with PhEP } \\
\hline 10 & 0.351 & 48 & 5.07 & 81.5 \\
\hline 20 & 0.445 & 44 & 5.33 & 80.7 \\
\hline 30 & 0.451 & 47 & 6.04 & 80.3 \\
\hline 40 & 0.464 & 30 & 4.07 & 77.2 \\
\hline \multicolumn{5}{|c|}{ For M-ER with CEH } \\
\hline 10 & 0.477 & 48 & 5.52 & 86.6 \\
\hline 20 & 0.522 & 56 & 5.93 & 86.7 \\
\hline 30 & 0.527 & 55 & 4.23 & 86.2 \\
\hline 40 & 0.541 & 53 & 4.83 & 86.1 \\
\hline \multicolumn{5}{|c|}{ For M-ER with FAGE } \\
\hline 10 & 0.532 & 51 & 4.37 & 79.7 \\
\hline 20 & 0.540 & 49 & 4.93 & 80.2 \\
\hline 30 & 0.527 & 50 & 5.73 & 78.2 \\
\hline 40 & 0.536 & 39 & 4.83 & 72 \\
\hline
\end{tabular}

product of MPS with crotonaldehyde which has a double unsaturated bond and more carbon number in the (-CO$\mathrm{CH}=\mathrm{CH}-\mathrm{CH}=\mathrm{CH}-\mathrm{CH}_{3}$ ) side group showed improved tensile strength and elongation at break compared to other MPSs. Thus, the MPSs having aliphatic ketone group presented better mechanical results compared to those having aromatic ketone group.

The results on the tensile strength and hardness are given in Table 4. The stress-strain curves of ER and MERs are represented in Figure 7. Breaking strain ratio and tensile strength for ER were found as $0.487 \%$ and $41.75 \mathrm{MPa}$, respectively. When ER was modified with EMP having a carbonyl group, its breaking strain ratio reached $0.559 \%$, which is the highest stretching value. It was observed that an increase in modifier amount caused an increase in stretching. The lowest stretching was observed with ER-PhEP and this is consistent with literature [29].

Tensile strengths of M-ERs modified up to $30 \%$ were observed to be higher than that of ER. The highest tensile strength was achieved with ER-EMP (with 10\% modifier content), which has a carbonyl group. The second highest was obtained with ER-FAGE that has alkene groups and the highest number of carbon atoms. In our previous study, we reported that all epoxy blends with various polymer types show higher values of tensile strength and elongation 


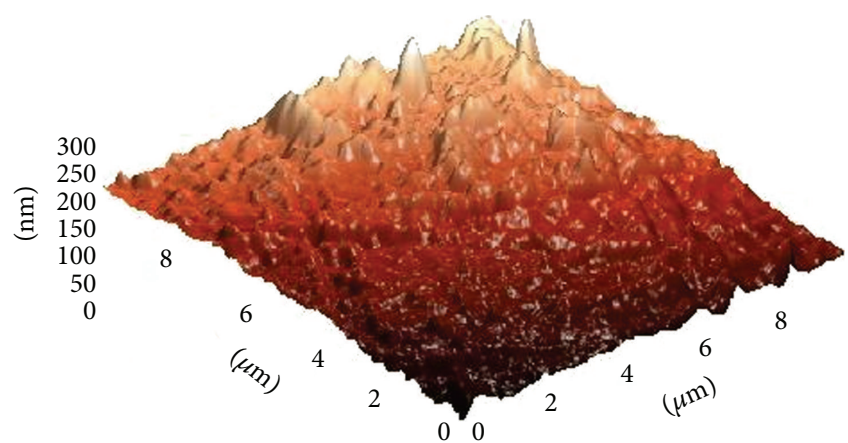

(a)

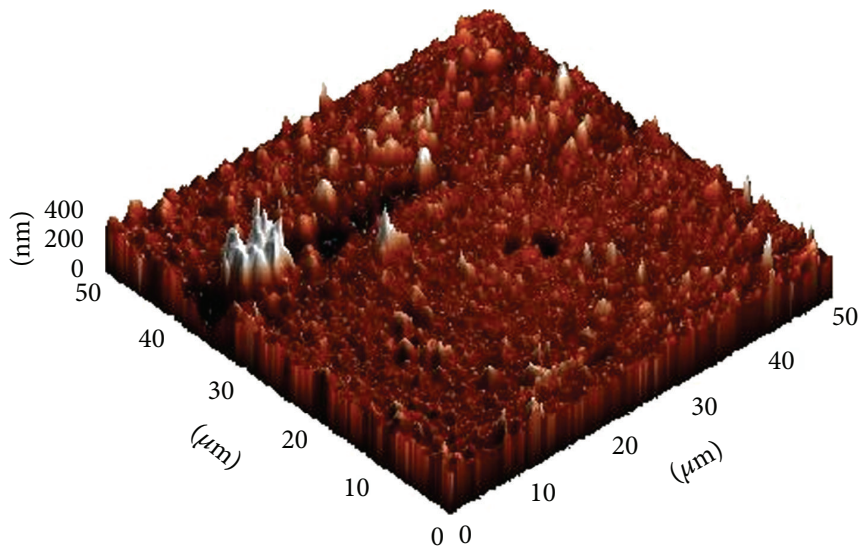

(c)

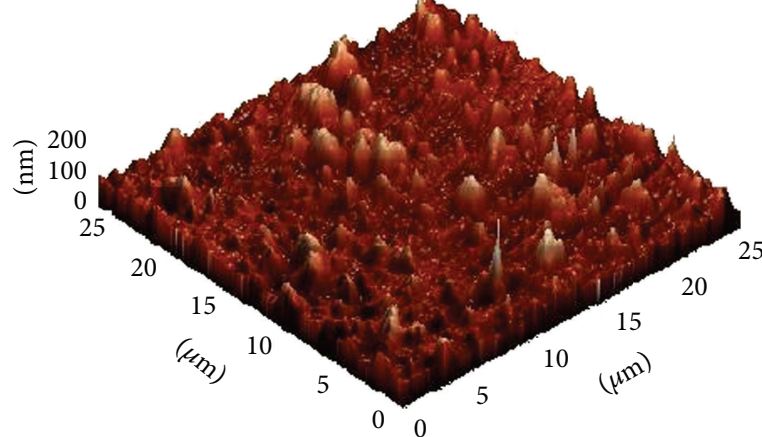

(b)

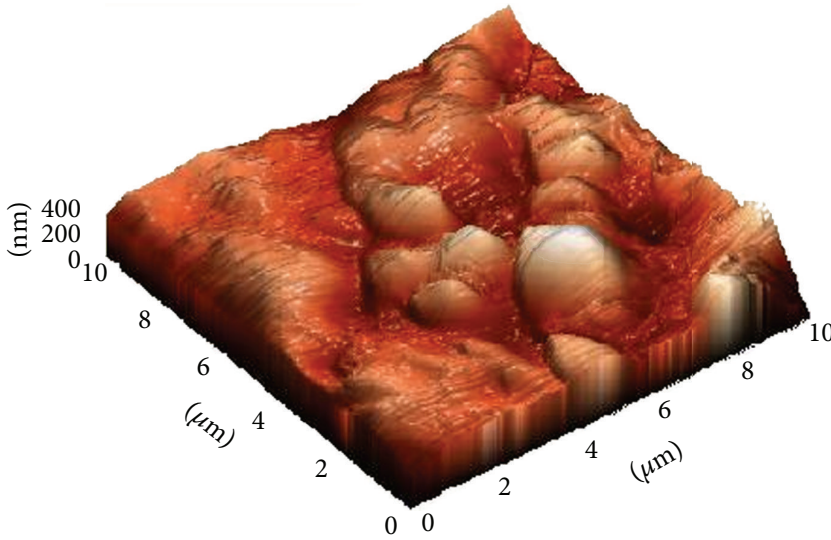

(d)

Figure 6: AFM images of M-ERs with (a) EMP, (b) PhEP, (c) CEH, and (d) FAGE.

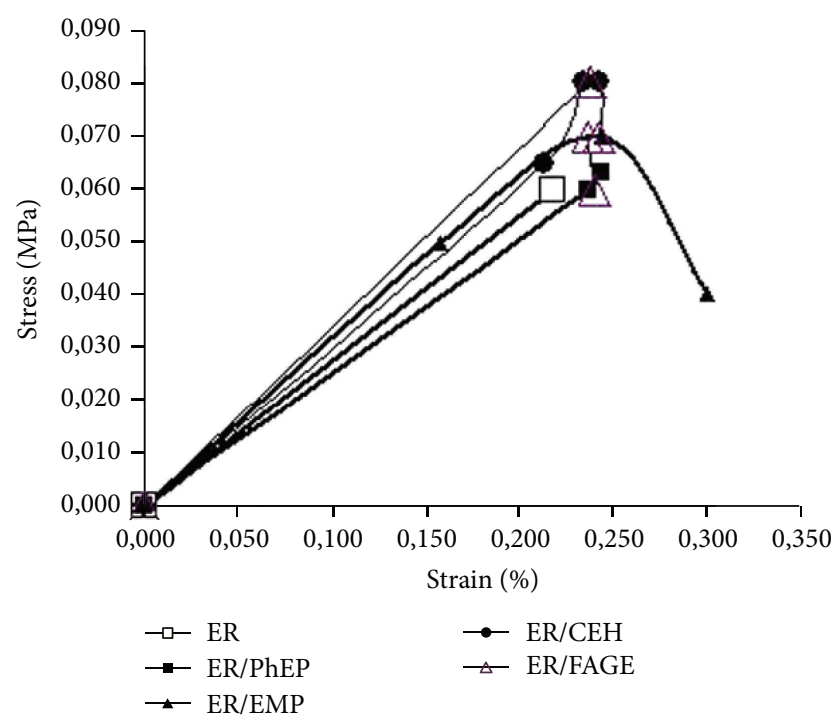

FIgURE 7: Tensile behaviour of neat ER and M-ERs.

at break than pure epoxy matrix due to the polar sidechain groups in the polymers used. Moreover, extent of these properties increased with the increase in the amounts of the polymers. Best results were obtained with oligo(ethers-esters)
[10]. Besides, the introduction of soft segments into brittle ERs dramatically reduced the internal stress and increased the strength [8]. Kunal et al. [30] explained the relationship between the fragility and side group structures in polymers. According to their comment, addition of bulky and inflexible side groups causes the polymers to become relatively fragile and also increases $T_{g}$. Therefore, the order of the tensile strength of M-ERs with $10 \%$ modifier was found to be EREMP $(59 \mathrm{MPa})>$ ER-FAGE $(51 \mathrm{MPa})>$ ER-PhEP and ER$\mathrm{CEH}(48 \mathrm{MPa})$ due to the polar groups in the chemical structures.

Brittle materials such as ceramic do not undergo plastic deformation and break under low tension [31]. Therefore, Young's modules of hard and brittle polymers are high while breaking strains of them are low [32]. Similarly, Young's modules of soft polymers are low while breaking strains of those are high [33]. In the present study, the optimum modifier contents were determined to be 10,20 , and $30 \%$ (wt.) for $\mathrm{CEH}, \mathrm{PhEP}$, and FAGE, respectively, in terms of the tensile strength and elasticity (Young's module) values. The order of the tensile strengths and elasticity modules of M-ERs was found as follows: ER-EMP > ER-CEH $>$ ER-FAGE $>$ ERPhEP.

Unlike metals, there is no correlation between hardness and tensile strength for elastomers. The tensile strength of an elastomer may increase or decrease as hardness value 
TABLE 5: TGA data of neat and M-ERs.

\begin{tabular}{lccccc}
\hline $\begin{array}{l}\text { Modifier } \\
\text { (30 wt.\%) }\end{array}$ & $\begin{array}{c}\text { IDT }^{*} \\
\left({ }^{\circ} \mathrm{C}\right)\end{array}$ & $\begin{array}{c}\text { SDT }^{* *} \\
\left({ }^{\circ} \mathrm{C}\right)\end{array}$ & $\begin{array}{c}T_{5} \\
\left({ }^{\circ} \mathrm{C}\right)\end{array}$ & $\begin{array}{c}T_{10} \\
\left({ }^{\circ} \mathrm{C}\right)\end{array}$ & $\begin{array}{c}T_{50} \\
\left({ }^{\circ} \mathrm{C}\right)\end{array}$ \\
\hline- & 100 & 250 & 173 & 262 & 358 \\
\hline \multicolumn{5}{c}{ Neat ER } \\
EMP & 100 & 261 & 195 & 270 & 376 \\
PhEP & 125 & 316 & 200 & 271 & 383 \\
CEH & 95 & 210 & 145 & 230 & 360 \\
FAGE & 100 & 241 & 166 & 260 & 364 \\
\hline * Initial decomposition temperature; ${ }^{* *}$ second decomposition temperature.
\end{tabular}

increases depending on the nature of the constituent components [33]. However, the hardness measurements show similar results for tensile tests because these are proportionally associated with each other in terms of mechanical properties [34]. As seen in Table 4, tensile strengths of MERs, which were modified up to $30 \%$, were higher than that of ER. The hardness of ER-EMP and ER-CEH were observed to be higher than those of other M-ERs, too.

In many materials, an applied stress (up to a certain limit) is directly proportional to a resulting strain, and a graph relating these two quantities yields a straight line. The linearelastic region is below the yield point. If a yield point is not easily identified on the stress-strain plot, it is defined to be 0 $0.2 \%$ of strain and is defined as the region of strain in which no yielding (permanent deformation) occurs [29]. As clearly seen in Figure 7, stress-strain curves of M-ERs were split in two as elastic and plastic regions compared to ER. Stress and strain increased proportionally in elastic region. Further increment of the strain caused a slight increment in stress. It is known that the increase in stress and strain proceeded to rise up to composite fracture. M-ERs represented broad stress-strain regions with respect to ER and this means that the addition of modifier enhanced its plasticity. The broadest strain region was obtained with ER-EMP and, accordingly, the highest elasticity modulus and stretching values from the tensile test were also achieved with this M-ER type.

3.3.4. Thermal Properties. Thermal analysis is an important analytical method to understand the structure-property relationships and thermal stability of the polymers. The nature of the substituents plays an important role in thermal stability. Polystyrenes (PS) modified with various aldehydes were reported to be more stable to thermal destruction than unmodified PS, depending on structure of active polyfunctional groups bound to the aromatic ring [28]. The principal characteristics and products of thermal degradation of a commercial ER prepared by the reaction of bisphenolA with epichlorohydrin have been studied by Grassie et al. Decomposition of the cross-linked resin occurred above $340^{\circ} \mathrm{C}$ and phenolic compounds appeared in the media [35].

In the present study, effect of the structure of modifying agent on the thermal properties of ER was investigated by using TGA analysis in the temperature range of $50-800^{\circ} \mathrm{C}$ and the results are given in Tables 5 and 6 . The ER and

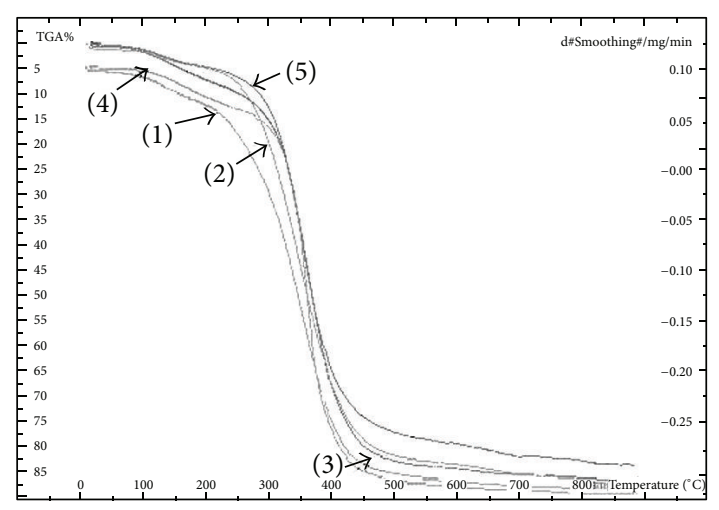

FIGURE 8: TGA curves of neat ER (1) and M-ERs with (2) FAGE, (3) EMP, (4) CEH, and (5) PhEP.

M-ERs underwent two-stage thermal degradation (Figure 8). First degradation stage of ER was observed at $100^{\circ} \mathrm{C}$ resulting from the dehydration of ER cured with polyamine. Second degradation stage was observed at $250^{\circ} \mathrm{C}$ occurring due to the degradation of bisphenol-A group.

$T_{5}, T_{10}$, and $T_{50}$ temperatures $(5,10$, and $50 \%$ weight loss, resp.) are the main identifiers of thermal stability of composites. The higher these temperatures are, the higher the thermal stability is. As clearly seen from the first (FDP) and second (SDP) degradation points and also $T_{5}, T_{10}$, and $T_{50}$ temperature values, modification with EMP and PhEP improved the thermal stability of ER (Table 5 ). The $T_{5}$ values of ER increased from $173^{\circ} \mathrm{C}$ to 195 and $200^{\circ} \mathrm{C}$ with these modifiers, respectively. The $T_{50}$ temperatures showed similar behaviours. On the other hand, these temperatures for the MERs with CEH and FAGE were found to be slightly lower than the temperatures for other M-ERs. Consequently, modifying with PhEP and EMP improved the thermal stability of ER while CEH and FAGE have slight effects on the property (Table 6). Fouassier and Rabek [36] reported that polymer systems with highly cross-linked network structures commonly exhibit greater thermal stability than the systems with lower cross-linking. Since ERs modified with EMP and PhEP showed higher curing degrees, their thermal stabilities were found to be higher than others, too. The order of the thermal stability of M-ERs with $30 \%$ modifier content is as follows: $\mathrm{PhEP}>\mathrm{EMP}>\mathrm{FAGE}>\mathrm{CEH}$. In a previous study comparing the thermal and mechanical properties of the epoxy systems, the ERs cured with aromatic DETDA (diethyltoluene diamine) had higher thermal properties at all cross-linking densities compared to those cured with DGEBA/TETA (triethylenetetramine). On the other hand, higher mechanical properties were obtained with DGEBA/TETA [37].

The residual char percentages of $12 \%, 14 \%, 15 \%$, and $17.5 \%$ were observed in the thermal decomposition $\left(T=800^{\circ} \mathrm{C}\right)$ of the ERs modified with FAGE, EMP, CEH, and PhEP, respectively, while it was determined as $9 \%$ for neat ER. The char yield can be used as a criterion for the evaluation of limiting oxygen index (LOI) of the cured resins in accordance with Van Krevelen and Hoftyzer equation [38]:

$$
\text { LOI }=17.5+0.4 \text { char yield }
$$


TABLE 6: Effect of modifier type on thermal properties of M-ERs.

\begin{tabular}{|c|c|c|c|c|c|c|c|c|}
\hline \multirow{2}{*}{$\begin{array}{l}\text { Modifier } \\
\text { (30 wt.\%) }\end{array}$} & \multicolumn{7}{|c|}{ Loss of weight (\%) } & \multirow{2}{*}{$\begin{array}{c}\text { Residual weight } \\
(\%) \\
800^{\circ} \mathrm{C}\end{array}$} \\
\hline & $200^{\circ} \mathrm{C}$ & $300^{\circ} \mathrm{C}$ & $350^{\circ} \mathrm{C}$ & $400^{\circ} \mathrm{C}$ & $450^{\circ} \mathrm{C}$ & $\begin{array}{c}\text { FSD }^{*} \\
{ }^{\circ} \mathrm{C}\end{array}$ & $\begin{array}{c}\text { SSD }^{* *} \\
{ }^{\circ} \mathrm{C}\end{array}$ & \\
\hline \multicolumn{9}{|c|}{ Neat ER } \\
\hline- & 7.5 & 15 & 33 & 67 & 77 & 5.26 & 79.94 & 9 \\
\hline \multicolumn{9}{|c|}{ Modified ERs } \\
\hline EMP & 6 & 12 & 34 & 64 & 73 & 7.78 & 79.03 & 14 \\
\hline PhEP & 5 & 11.5 & 27 & 55 & 70 & 9.16 & 78.07 & 17.5 \\
\hline $\mathrm{CEH}$ & 8 & 22 & 45 & 69 & 81.5 & 7.18 & 82.26 & 15 \\
\hline FAGE & 5.2 & 17.5 & 41 & 66.5 & 77.5 & 4.59 & 82.10 & 12 \\
\hline
\end{tabular}

*First-step degradation; ${ }^{* *}$ second-step degradation.

The LOI values calculated using (5) were 22.3, 23.1, 23.5, and 24.5 for FAGE, EMP, CEH, and PhEP modifiers, respectively. The higher the LOI value, the better the nonflammability property of the material. Air contains approximately $21 \%$ oxygen; therefore, LOI value greater than 21 indicates a nonflammable nature. However, any material with an LOI of less than 21 will probably support burning in an open-air situation. All M-ERs prepared in this study had LOI values higher than 21, which means that FAGE, EMP, CEH, and PhEP enhanced the flame retardancy of epoxy.

3.3.5. Coating Properties. The versatile properties of ERs make them valuable, particularly in human daily life and specific applications. In particular, industrial maintenance coating applications constitute the largest epoxy coating market globally. The main function of these coatings in applications is the protection of the metal and concrete structures from aggressive environmental conditions and for their long term use. Resins based on bisphenol-A and bisphenol-F epoxies are commonly used. Likewise aliphatic polyamines, aliphatic and aromatic amines, ketimines, phenalkamines, amidoamine, and polyamide resins can be used as curing agents for ER. Special modifiers and curing agents should be used to produce specific properties [17].

(1) Water Sorption. The water absorbed by the materials may change or deteriorate the properties of epoxy materials since highly cross-linked ERs are hydrophilic [38]. Moreover, depending on the amount of water absorbed, it may also affect the properties of the coating material related to anticorrosive protection [39]. Sorption of the liquid by the cured epoxy may lead to chemical changes as well as mechanical changes. For fully cured ERs, liquid sorption has led to failures such as swelling, modulus loss, strength loss, stress cracking, weight gain, gloss loss, and hardness loss. The amount of water in cured ER is strongly dependent on the chemical structure of the material, filler type and amount, and degree of cross-linking and curing agents [40, 41]. A polymer chain having an epoxy backbone is substantially better than many other resin types at resisting the effects of water. The water absorption percentages of various ERs after 24-hour immersion were reported by Licari to be $0.5-1.0 \%$ depending on the formulation and type of resin [42].
The water sorption properties of ER and M-ERs (with $30 \%$ (wt.) modifier content) were tested in deionized water for 30 days at room temperature. Preliminary studies showed that this is a sufficient time for reaching the equilibrium for all types of M-ERs studied. In addition, the effect of temperature on water sorption was investigated at $45^{\circ} \mathrm{C}$. Figure 9 shows the variation in water sorption over time and temperature. As previously mentioned, water sorption was determined by using gravimetric method. Water sorption equilibrium was obtained in 12 days for ER and ER-PhEP, in 20 days for ERFAGE, in 22 days for ER-CEH, and in 26 days for ER-EMP.

The equilibrium water content of ER was measured as $0.81 \%$, which is consistent with the reports in the literature [42]. Soles et al. [43] explained that the water molecules would mostly bond to the polar groups in the ER. Mijović and Zhang [44] mentioned that more than $95 \%$ of water molecules would reside near the polar groups in the epoxy network.

The order of the water sorption percentages of M-ERs having different functional groups was ER-EMP $>$ ER-CEH $>$ ER-FAGE $>$ ER-PhEP. This order is also in agreement with the tensile strength results. At the end of the 30 days, the highest water sorption was observed to be with the M-ER having ketone group (ER-EMP) as $4.22 \%$. On the other hand, the most promising result was achieved with ER-PhEP as its water content was $0.83 \%$ which is almost equal to that of ER (Figure 9(a)).

To understand and improve the performance of ER at harsh environmental conditions, it is essential to investigate the influence of temperature on the water equilibrium over $20-25^{\circ} \mathrm{C}$. As seen from Figure 9(b), a fast increment in water sorption was observed with the increase in temperature and the equilibrium was reached in $7-8$ days at $45^{\circ} \mathrm{C}$. After this period, water sorption of ER doubled and finally was found to be $1.8 \%$. Similar to the results obtained at room temperature, water sorption of ER-PhEP at $45^{\circ} \mathrm{C}$ was close to that of ER. It is clearly seen that the orders of water sorption percentages of M-ERs were similar when the results for both temperatures were compared.

Water desorption properties were also examined at $45^{\circ} \mathrm{C}$. As seen from Figure 9(c), water desorption studies of EREMP and ER-PhEP were completed in 7-8 days while those 


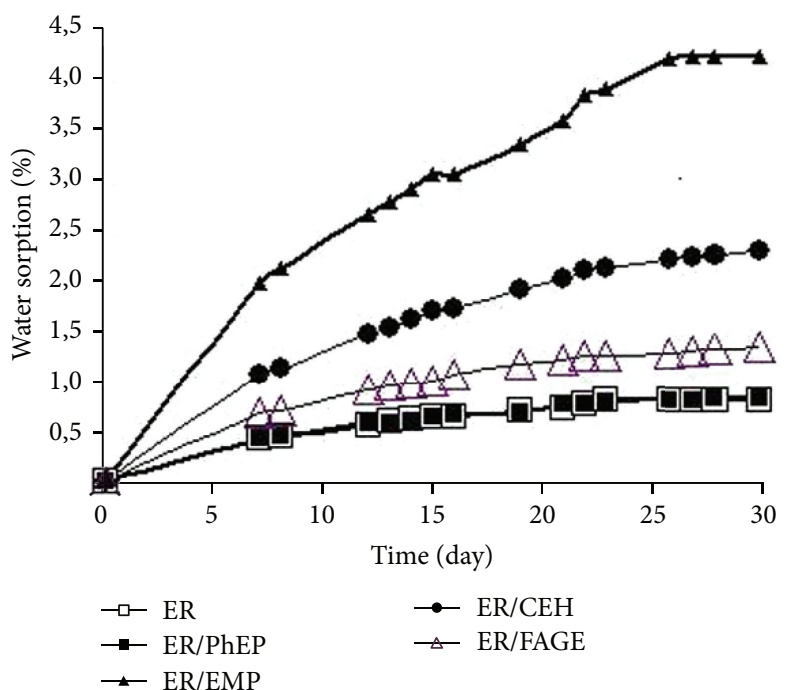

(a)

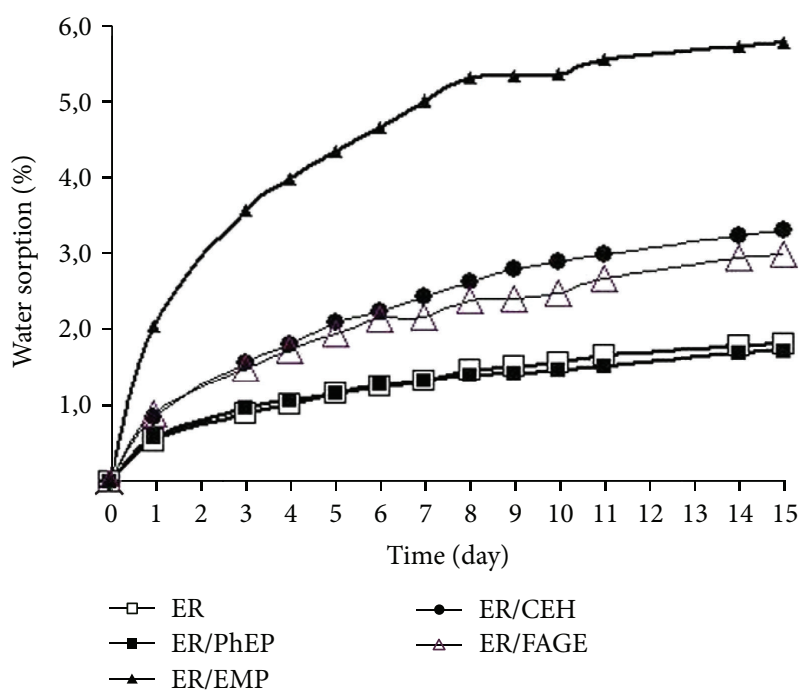

(b)

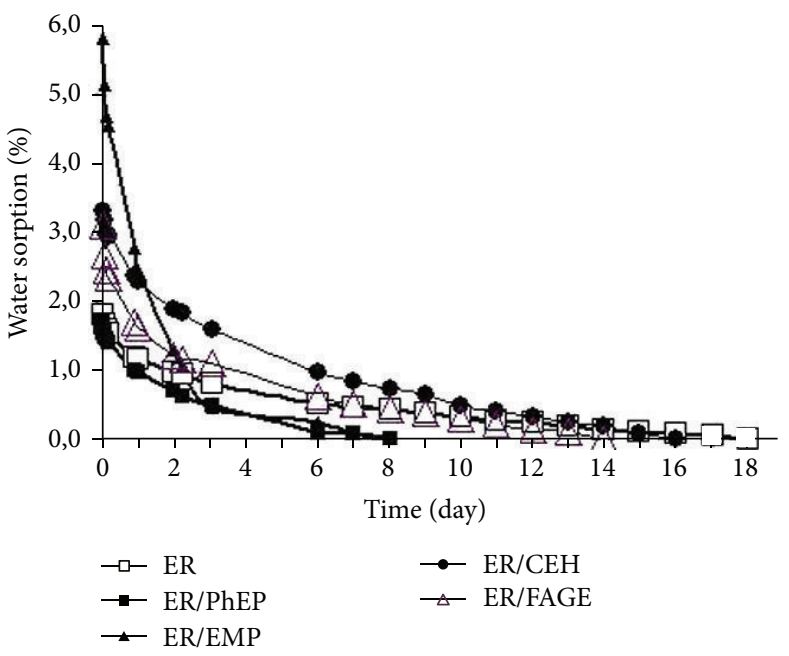

(c)

Figure 9: Water sorption of neat ER and M-ERs: (a) at room temperature; (b) at $45^{\circ} \mathrm{C}$; (c) desorption at $45^{\circ} \mathrm{C}$.

of ER-FAGE and ER-CEH were finished in 14-16 days, which were earlier than that of ER. The ER-EMP had the highest water sorption and desorption. Water desorption percentages decreased in the order of ER-EMP $\approx$ ER-PhEP $>$ ER-FAGE $>$ ER-CEH $>$ ER. Thus, the results indicated that modifying ER with EMP and PhEP enhanced its water desorption property.

(2) Adhesion and Corrosion Properties. Adhesion between the polymer and the substrate layer is controlled by the chemical groups. The increase in polarity of the chemical group causes an increase in molecular forces between the surface of the substrate and polymer. This also results in an increase in adhesion strength [45]. Since polar groups such as epoxides, hydroxyls, and carboxyls in polymeric backbones are adhesion promoters, epoxies adhere well to most metals and alloys, plastics, and ceramics. Shreepathi et al. mentioned that equilibrium water content is also an important factor for the corrosion resistance of epoxy coatings. For example, coatings with lower equilibrium water content showed better corrosion resistances [46].
The adhesion and chemical resistance properties of bisphenol-A type ERs are well known [1, 42]. In the present study, adhesion and corrosion tests were performed for the M-ERs with $30 \%$ modifier content. An image of the metal plates coated with M-ERs and the related data are shown in Figure 10 and Table 7, respectively. Accordingly, all M-ERs showed $100 \%$ adhesion to metal surface. This is due to the increased polarity of epoxy with the modifiers. Furthermore, Beholz et al. [47] stated that modifying the surface of poly(p-phenylene sulfide) with polar groups increased the surface roughness, which also resulted in an increased surface adhesiveness. Likewise, AFM images of the M-ERs show that the surface roughness significantly increased due to the modification with EMP, PhEP, CEH, and FAGE and this can also be a reason for the increased surface adhesiveness (Figure 6).

Corrosion properties were examined by keeping the samples in 5\% solutions of $\mathrm{NaCl}, \mathrm{NaOH}$, and $\mathrm{HCl}$ for 15 days (open air). After the completion of soaking, physical 


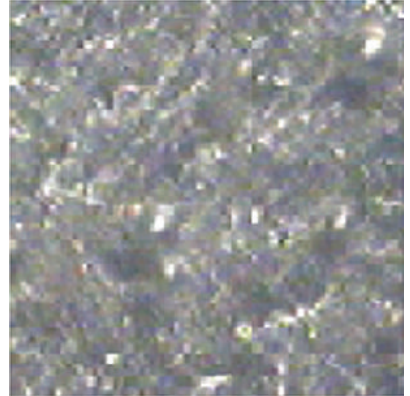

(a)

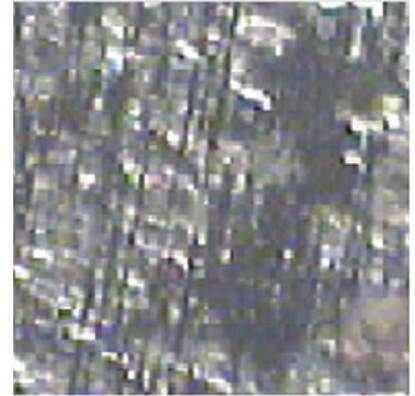

(b)

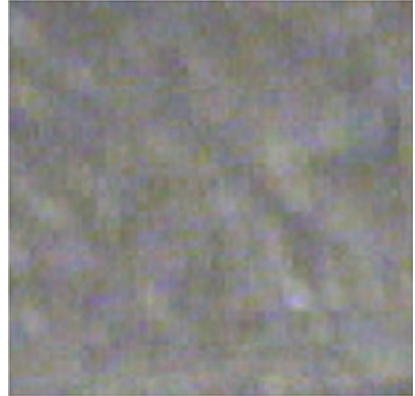

(c)

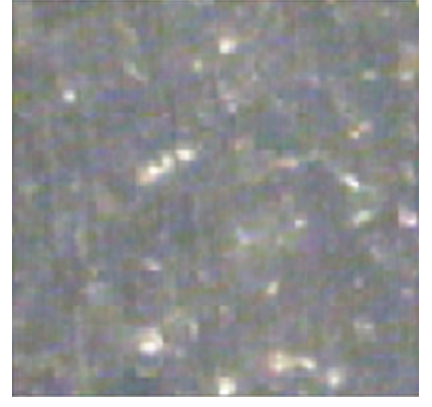

(d)

Figure 10: Polarizing microscope images (mag. 2.52x) of M-ERs with (a) EMP, (b) PhEP, (c) CEH, and (d) FAGE.

TABLE 7: Adhesion and corrosion properties of M-ERs.

\begin{tabular}{lccccc}
\hline \multirow{2}{*}{ Modifier } & $\begin{array}{c}\text { Adhesion } \\
(\%)\end{array}$ & \multicolumn{5}{c}{ Corrosion resistance } \\
& $5 \% \mathrm{NaCl}$ & $5 \% \mathrm{NaOH}$ & $5 \% \mathrm{HCl}$ & Air \\
\hline EMP & 100 & ++ & ++ & ++ & ++ \\
PhEP & 100 & ++ & ++ & ++ & ++ \\
CEH & 100 & ++ & +- & +- & ++ \\
FAGE & 100 & ++ & +- & +- & ++ \\
\hline
\end{tabular}

++ : high resistance, +- : medium resistance.

appearances of the M-ERs were tested and no change was observed in the samples. Similarly, coatings displayed a considerable resistance to salt water. Liu et al. demonstrated that increasing the cross-linking density may improve the corrosion resistance of coatings [48]. Among the M-ERs, the highest curing degree was obtained with ER-EMP and this M-ER was more resistant to acid and alkaline medium compared to other M-ERs with FAGE and CEH. Although FAGE had a higher curing degree than PhEP, its corrosion resistance to acids and bases was lower than the M-ER with aromatic group. This is most probably due to the ester bonds in FAGE which can be degraded by hydrolysis at extreme $\mathrm{pH}$ values. It is known that the lower concentration of ester groups in polymer causes the higher corrosion resistance. But ERs having aromatic ring show high durability to acids and bases [49]. Therefore, although the curing degree of M-ER with PhEP had a close value to that with $\mathrm{CEH}$ and lower value than that with FAGE, it has a better resistance than the others.

\section{Conclusion}

In the present study, ER was modified using four different epoxide compounds to improve mechanical, thermal, and coating properties. It was observed that tensile strengths of the M-ERs with 30\% (wt.) modifier content were higher than that of ER. Similarly, hardness values of the M-ERs were also higher compared to the neat ER. The M-ERs displayed broad stress-strain regions with respect to the ER, which means that the modification enhanced the plasticity of neat ER. Thermal stability of ER was also improved with the modifiers PhEP and EMP, while CEH and FAGE had negligible effects on this property. The best water sorption percentage was achieved with ER-PhEP (0.83\%), which was almost equal to that obtained with neat ER $(0.81 \%)$. The water sorption percentage of the other M-ERs varied between $1.34 \%$ and $4.22 \%$. Water desorption percentages decreased in the order of ER-EMP $\approx$ ER-PhEP $>$ ER-FAGE $>$ ER-CEH $>$ ER. The $M-E R$ coatings displayed a considerable resistance to acidic, basic, and salt water. The ER-EMP and ER-PhEP were more resistant to acid and alkaline medium compared to the ER and other M-ERs. As a result, significant enhancements were obtained in the properties of ER with the modification.

\section{Competing Interests}

The authors declare that there is no conflict of interests regarding the publication of this paper.

\section{References}

[1] C. A. May and G. Y. Tanaka, Epoxy Resin Chemistry and Technology, Marcel Dekker, New York, NY, USA, 1973.

[2] G. Tang, Z. Yan, L. Ma, and X. Huang, "Modification of urushiol derivatives by liquid crystal epoxy resin," International Journal of Polymer Science, vol. 2015, Article ID 132809, 8 pages, 2015.

[3] N. Rajagopalan and A. S. Khanna, "Effect of methyltrimethoxy silane modification on yellowing of epoxy coating on UV (B) exposure," Journal of Coatings, vol. 2014, Article ID 515470, 7 pages, 2014.

[4] U. G. Rane, A. A. Sabnis, and V. V. Shertukde, "Synthesis and characterization of imide containing hybrid epoxy resin with improved mechanical and thermal properties," International Journal of Polymer Science, vol. 2014, Article ID 941793, 10 pages, 2014.

[5] F.-L. Jin and S.-J. Park, "Impact-strength improvement of epoxy resins reinforced with a biodegradable polymer," Materials Science and Engineering A, vol. 478, no. 1-2, pp. 402-405, 2008.

[6] H. Miyagawa, A. K. Mohanty, M. Misra, and L. T. Drzal, "Thermo-physical and impact properties of epoxy containing epoxidized linseed oil," Macromolecular Materials and Engineering, vol. 289, no. 7, pp. 636-641, 2004.

[7] Z.-K. Chen, G. Yang, J.-P. Yang, S.-Y. Fu, L. Ye, and Y.-G. Huang, "Simultaneously increasing cryogenic strength, ductility and impact resistance of epoxy resins modified by n-butyl glycidyl ether," Polymer, vol. 50, no. 5, pp. 1316-1323, 2009. 
[8] G. Yang, S.-Y. Fu, and J.-P. Yang, "Preparation and mechanical properties of modified epoxy resins with flexible diamines," Polymer, vol. 48, no. 1, pp. 302-310, 2007.

[9] F. L. Barcia, T. P. Amaral, and B. G. Soares, "Synthesis and properties of epoxy resin modified with epoxy-terminated liquid polybutadiene," Polymer, vol. 44, no. 19, pp. 5811-5819, 2003.

[10] G. Ahmetli, H. Deveci, U. Soydal, S. P. Gurler, and A. Altun, "Epoxy resin/polymer blends: improvement of thermal and mechanical properties," Journal of Applied Polymer Science, vol. 125, no. 1, pp. 38-45, 2012.

[11] S. Kocaman and G. Ahmetli, "A study of coating properties of biobased modified epoxy resin with different hardeners," Progress in Organic Coatings, vol. 97, pp. 53-64, 2016.

[12] U. Soydal, M. E. Marti, S. Kocaman, and G. Ahmetli, "Evaluation of sugar mill lime waste in biobased epoxy composites," Polymer Composites, 2016.

[13] G. Ahmetli, Z. Yazicigil, and U. Soydal, "Modification of the epoxy resin with epoxide and ester group containing oligomers and compounds," Proceedings of the Estonian Academy of Sciences, vol. 64, no. 1, pp. 71-76, 2015.

[14] Z. Yazicigil and G. Ahmetli, "Synthesis of the fatty acid compounds obtained from sunflower oil refining products," Journal of Applied Polymer Science, vol. 108, no. 1, pp. 541-547, 2008.

[15] GOST, "Adhesion determination method," Government Standard 1540-78, Moscow, Russia, 1978.

[16] G. Ahmetli, H. Deveci, A. Altun, and R. Kurbanli, "Corrosion and thermal characterization of styrene based copolymers," Progress in Organic Coatings, vol. 70, no. 1, pp. 9-15, 2011.

[17] M. S. Bhatnagar, Epoxy Resins (Overview), The Polymeric Materials Encyclopedia, CRC Press, 1996.

[18] H. A. Pham and M. J. Marks, "Epoxy resins," in Encyclopedia of Polymer Science and Technology, version 9, John Wiley \& Sons, New York, NY, USA, 2003.

[19] M. Abdalla, D. Dean, P. Robinson, and E. Nyairo, "Cure behavior of epoxy/MWCNT nanocomposites: the effect of nanotube surface modification," Polymer, vol. 49, no. 15, pp. 3310-3317, 2008.

[20] K.-T. Lau, M. Lu, C.-K. Lam, H.-Y. Cheung, F.-L. Sheng, and H.-L. Li, "Thermal and mechanical properties of single-walled carbon nanotube bundle-reinforced epoxy nanocomposites: the role of solvent for nanotube dispersion," Composites Science and Technology, vol. 65, no. 5, pp. 719-725, 2005.

[21] D. Y. Shen, The Application of the Fourier Transform Infrared Spectroscopy in Polymer Study, Academic Press, Beijing, China, 1982.

[22] S. Jana and W.-H. Zhong, "FTIR study of ageing epoxy resin reinforced by reactive graphitic nanofibers," Journal of Applied Polymer Science, vol. 106, no. 5, pp. 3555-3563, 2007.

[23] F. Fraga, E. C. Vazquez, E. Rodríguez-Núñez, and J. M. Martínez-Ageitos, "Curing kinetics of the epoxy system diglycidyl ether of bisphenol A/isophoronediamine by Fourier transform infrared spectroscopy," Polymers for Advanced Technologies, vol. 19, no. 11, pp. 1623-1628, 2008.

[24] Z. Wang, X. Yang, Q. Wang et al., "Epoxy resin nanocomposites reinforced with ionized liquid stabilized carbon nanotubes," International Journal of Smart and Nano Materials, vol. 2, no. 3, pp. 176-193, 2011.

[25] C. V. Hare, Protective Coatings: Fundamentals of Chemistry and Composition, Technology Publishing, Pittsburg, Calif, USA, 1994.
[26] J. E. Brady, T. Dürig, and S. S. Shang, "Polymer properties and characterization," in Developing Solid Oral Dosage Forms Pharmaceutical Theory and Practice, Y. Qui, L. Lui, Y. Chen, G. G. Z. Zhang, and W. Porter, Eds., chapter 9, Elsevier, New York, NY, USA, 2009.

[27] S. Sethuraman, L. S. Nair, S. El-Amin et al., "Mechanical properties and osteocompatibility of novel biodegradable alanine based polyphosphazenes: side group effects," Acta Biomaterialia, vol. 6, no. 6, pp. 1931-1937, 2010.

[28] A. Cerit, G. Ahmetli, and R. Kurbanli, "Effect of unsaturated keto-groups on physico-mechanical and thermal properties of modified polystyrene," Journal of Applied Polymer Science, vol. 121, no. 2, pp. 1193-1202, 2011.

[29] F. P. Beer, E. R. Johnston, J. T. De Wolf, and D. Mazurek, Mechanics of Materials, McGraw-Hill, New York, NY, USA, 5th edition, 2009.

[30] K. Kunal, C. G. Robertson, S. Pawlus, S. F. Hahn, and A. P. Sokolov, "Role of chemical structure in fragility of polymers: a qualitative picture," Macromolecules, vol. 41, no. 19, pp. 7232$7238,2008$.

[31] F. W. Billmeyer, Textbook of Polymer Science, WileyInterscience, New York, NY, USA, 3rd edition, 1984.

[32] S. Maiti, P. Banerjee, S. Purakayastha, and B. Ghosh, "Silicondoped carbon semiconductor from rice husk char," Materials Chemistry and Physics, vol. 109, no. 1, pp. 169-173, 2008.

[33] S. Gunasekaran, R. K. Natarajan, and A. Kala, "FTIR spectra and mechanical strength analysis of some selected rubber derivatives," Spectrochimica Acta-Part A: Molecular and Biomolecular Spectroscopy, vol. 68, no. 2, pp. 323-330, 2007.

[34] G. Ahmetli, H. Deveci, U. Soydal, A. Seker, and R. Kurbanli, "Coating, mechanical and thermal properties of epoxy toluene oligomer modified epoxy resin/sepiolite composites," Progress in Organic Coatings, vol. 75, no. 1-2, pp. 97-105, 2012.

[35] N. Grassie, M. I. Guy, and N. H. Tennent, "Degradation of epoxy polymers: part 1-products of thermal degradation of bisphenol-A diglycidyl ether," Polymer Degradation and Stability, vol. 12, no. 1, pp. 65-91, 1985.

[36] J. P. Fouassier and J. F. Rabek, Radiation Curing in Polymer Science and Technology: Fundamentals and Methods, Elsevier, London, UK, 1993.

[37] F. Jeyranpour, G. Alahyarizadeh, and B. Arab, "Comparative investigation of thermal and mechanical properties of crosslinked epoxy polymers with different curing agents by molecular dynamics simulation," Journal of Molecular Graphics and Modelling, vol. 62, pp. 157-164, 2015.

[38] D. W. Van-Krevelen and P. J. Hoftyzer, Properties of Polymers, Elsevier, New York, NY, USA, 2nd edition, 1976.

[39] J. B. Bajat, V. B. Mišković-Stanković, and Z. Kačarević-Popović, "Corrosion stability of epoxy coatings on aluminum pretreated by vinyltriethoxysilane," Corrosion Science, vol. 50, no. 7, pp. 2078-2084, 2008.

[40] S.-Y. Zhang, Y.-F. Ding, S.-J. Li, X.-W. Luo, and W.-F. Zhou, "Effect of polymeric structure on the corrosion protection of epoxy coatings," Corrosion Science, vol. 44, no. 4, pp. 861-869, 2002.

[41] L. Li, Y. Yu, Q. Wu, G. Zhan, and S. Li, "Effect of chemical structure on the water sorption of amine-cured epoxy resins," Corrosion Science, vol. 51, no. 12, pp. 3000-3006, 2009.

[42] J. J. Licari, Coating Materials for Electronic Applications, Noyes Publications, Park Ridge, NJ, USA, 2003. 
[43] C. L. Soles, F. T. Chang, B. A. Bolan, H. A. Hristov, D. W. Gidley, and A. F. Yee, "Contributions of the nanovoid structure to the moisture absorption properties of epoxy resins," Journal of Polymer Science Part B: Polymer Physics, vol. 36, no. 17, pp. 3035-3048, 1998.

[44] J. Mijović and H. Zhang, "Molecular dynamics simulation study of motions and interactions of water in a polymer network," The Journal of Physical Chemistry B, vol. 108, no. 8, pp. 2557-2563, 2004.

[45] F. Awaja, M. Gilbert, G. Kelly, B. Fox, and P. J. Pigram, "Adhesion of polymers," Progress in Polymer Science, vol. 34, no. 9, pp. 948968, 2009.

[46] S. Shreepathi, S. M. Naik, and M. R. Vattipalli, "Water transportation through organic coatings: correlation between electrochemical impedance measurements, gravimetry, and water vapor permeability," Journal of Coatings Technology Research, vol. 9, no. 4, pp. 411-422, 2012.

[47] L. G. Beholz, C. L. Aronson, and A. Zand, "Adhesion modification of polyolefin surfaces with sodium hypochlorite in acidic media," Polymer, vol. 46, no. 13, pp. 4604-4613, 2005.

[48] M. Liu, X. Mao, H. Zhu, A. Lin, and D. Wang, "Water and corrosion resistance of epoxy-acrylic-amine waterborne coatings: effects of resin molecular weight, polar group and hydrophobic segment," Corrosion Science, vol. 75, pp. 106-113, 2013.

[49] A. K. Kulshreshtha and C. Vasile, Handbook of Polymer Blends and Composites, Rapra Technology Limited, Shrewsbury, UK, 2002. 

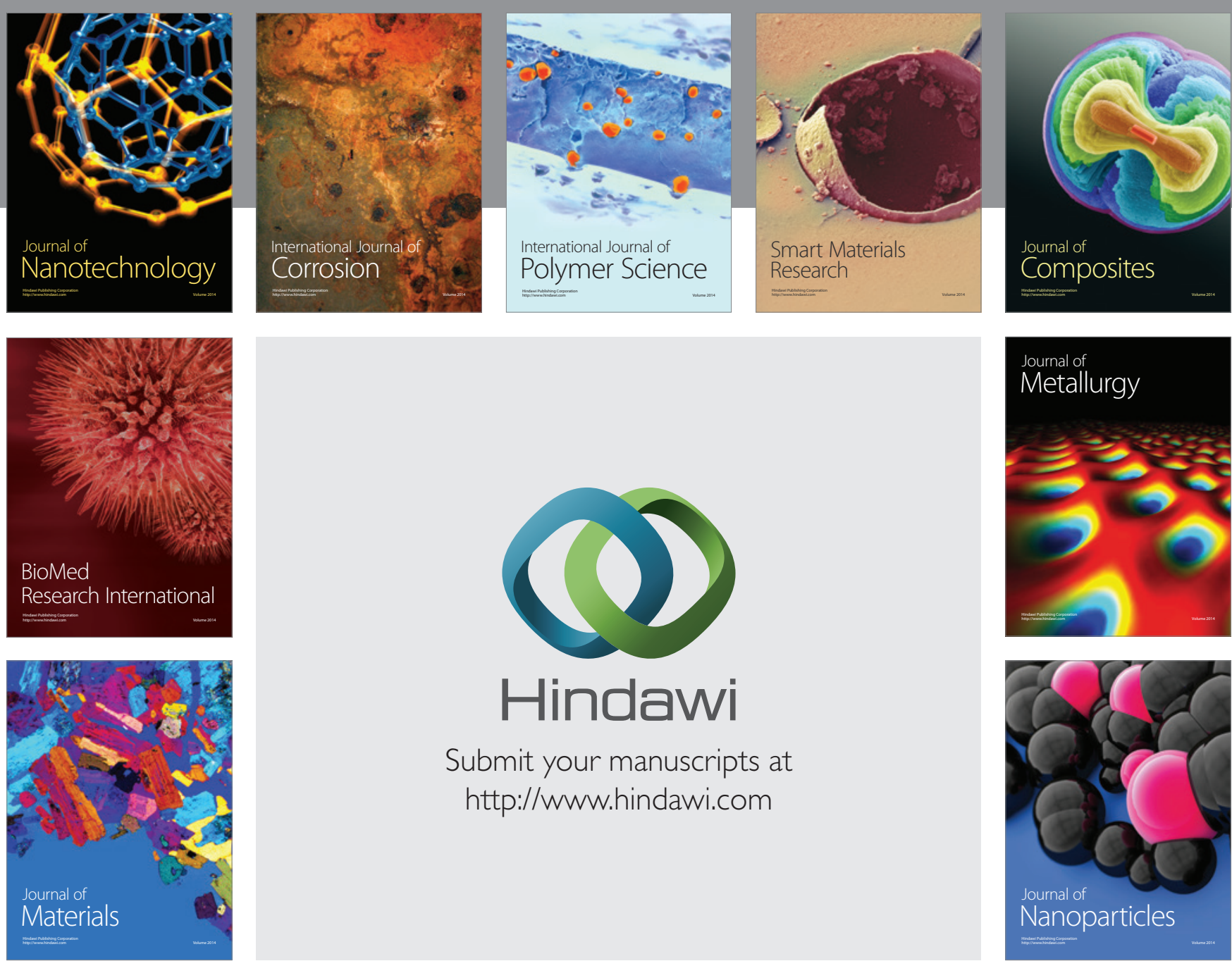

\section{Hindawi}

Submit your manuscripts at

http://www.hindawi.com

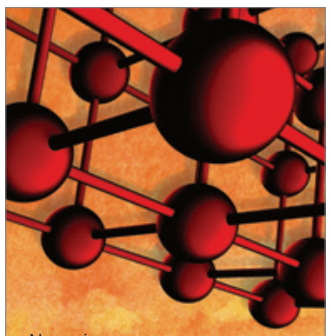

Materials Science and Engineering
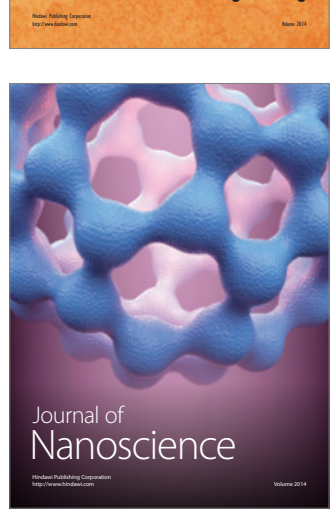
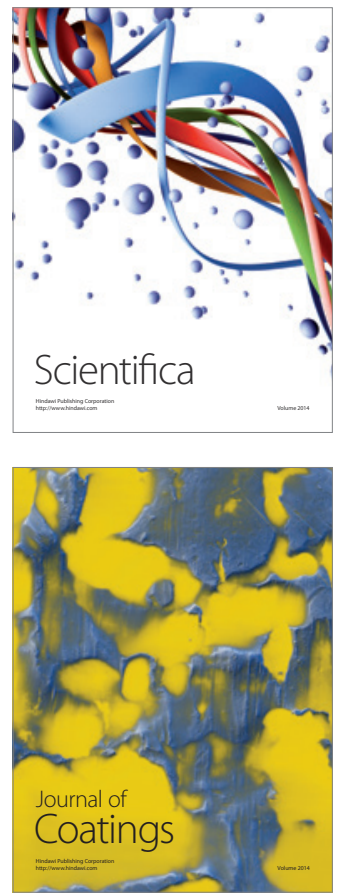
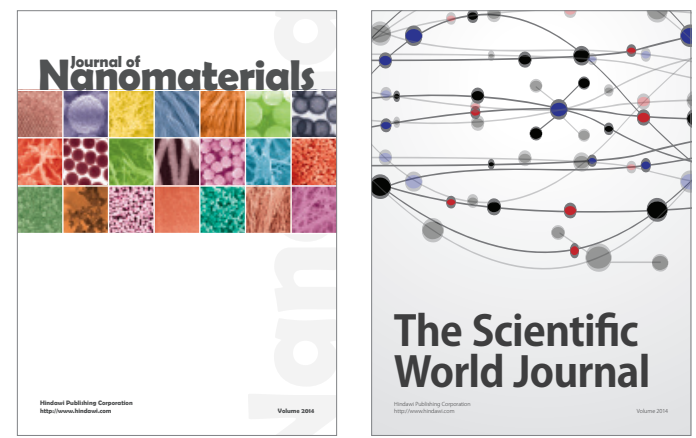

The Scientific World Journal
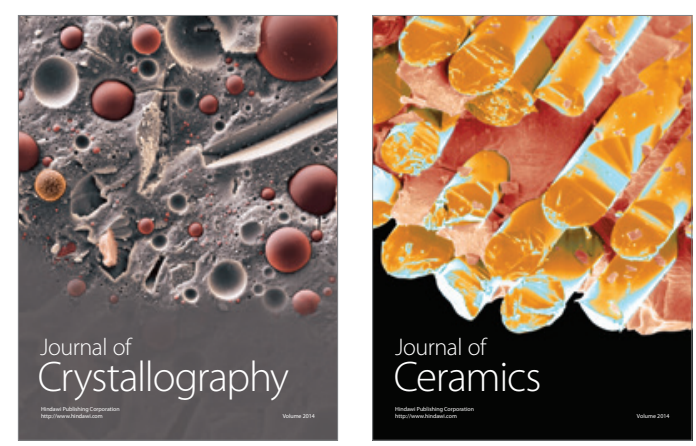
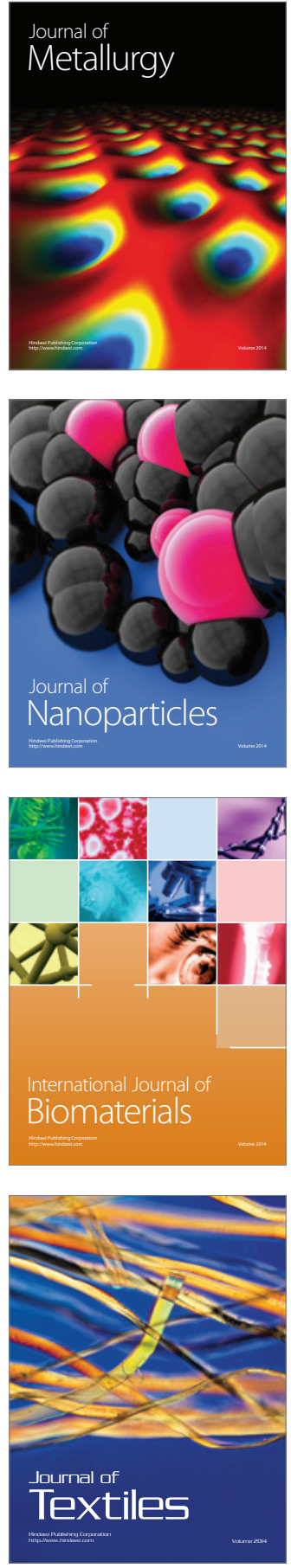